Published in final edited form as:

J Gastrointest Surg. 2012 January ; 16(1): 16-25. doi:10.1007/s11605-011-1741-1.

\title{
How Much Pharyngeal Exposure Is "Normal"? Normative Data for Laryngopharyngeal Reflux Events Using Hypopharyngeal Multichannel Intraluminal Impedance (HMII)
}

\section{Toshitaka Hoppo,}

Division of Thoracic and Foregut Surgery, Department of Cardiothoracic Surgery, University of Pittsburgh Medical Center, Shadyside Medical Center, Suite 715, 5200 Centre Avenue, Pittsburgh, PA 15232, USA

\author{
Alejandro F. Sanz, \\ Division of Thoracic and Foregut Surgery, Department of Cardiothoracic Surgery, University of \\ Pittsburgh Medical Center, Shadyside Medical Center, Suite 715, 5200 Centre Avenue, \\ Pittsburgh, PA 15232, USA
}

\section{Katie S. Nason,}

Division of Thoracic and Foregut Surgery, Department of Cardiothoracic Surgery, University of Pittsburgh Medical Center, Shadyside Medical Center, Suite 715, 5200 Centre Avenue, Pittsburgh, PA 15232, USA

\section{Thomas L. Carroll,}

Department of Otolaryngology, Tufts Medical Center, Boston, MA, USA

\section{Clark Rosen,}

Department of Otolaryngology, University of Pittsburgh Medical Center, Pittsburgh, PA, USA

\section{Daniel P. Normolle,}

Department of Biostatistics, Graduate School of Public Health, University of Pittsburgh,

Pittsburgh, PA, USA

\section{Nicholas J. Shaheen, \\ Department of Medicine, University of North Carolina, Chapel Hill, NC, USA}

James D. Luketich, and

Division of Thoracic and Foregut Surgery, Department of Cardiothoracic Surgery, University of Pittsburgh Medical Center, Shadyside Medical Center, Suite 715, 5200 Centre Avenue, Pittsburgh, PA 15232, USA

\section{Blair A. Jobe}

Division of Thoracic and Foregut Surgery, Department of Cardiothoracic Surgery, University of Pittsburgh Medical Center, Shadyside Medical Center, Suite 715, 5200 Centre Avenue, Pittsburgh, PA 15232, USA, jobeba@upmc.edu

\footnotetext{
(C) 2011 The Society for Surgery of the Alimentary Tract Correspondence to: Blair A. Jobe.

This paper was presented at the 52nd annual meeting of The Society for Surgery of Alimentary Tract, May 8, 2011, Chicago, IL.
} 


\section{Abstract}

Background-Laryngopharyngeal reflux (LPR) can cause atypical symptoms, asthma, and pulmonary fibrosis. The aim of this study was to establish the normative data for LPR using hypopharyngeal multichannel intraluminal impedancepH (HMII).

Methods-Asymptomatic subjects underwent endoscopy followed by 24-h HMII using a specialized impedance catheter configured to detect LPR before and after a 2-week course of proton pump inhibitors (PPI). Subjects were excluded if they had esophageal pathology or a positive DeMeester score. A cohort of 24 LPR patients who had a complete response to treatment was used for comparison with the normative data.

Results-Forty subjects were enrolled. Thirty-four subjects completed one, and 25 completed both HMII testing periods off and on PPI. There was no difference in the total number of reflux events between off and on PPI [22 (8-32) and 24 (10-28), respectively, $p=0.89$ ]. The 95th percentiles of LPR off and on PPI were 0 and 1, respectively. All patients with treatment responsive LPR had pre-treatment HMII values of LPR greater than the 95th percentile.

Conclusion-LPR events are rare in an asymptomatic population. One or more LPR events should be considered abnormal in patients with LPR symptoms regardless of whether there is a positive DeMeester score.

\section{Keywords}

Laryngopharyngeal reflux; Hypopharyngeal multichannel intraluminal impedance-pH; Normative data; Full column reflux

\section{Introduction}

The direct effects of refluxed gastric contents on the upper aerodigestive tract cause laryngopharyngeal reflux (LPR), thus resulting in a different set of symptoms and clinical course than those with typical gastroesophageal reflux disease (GERD). As few as three episodes of laryngeal reflux per week can cause severe laryngeal inflammation and injury. ${ }^{1}$ In addition, reflux related distal esophageal injury can result in bronchoconstriction and cough which are mediated by vagal afferent fibers. ${ }^{2}$ LPR is associated with atypical symptoms such as chronic cough, hoarseness, throat clearing, sore throat, voice fatigue, and globus sensation as well as pulmonary diseases such as asthma and pulmonary fibrosis. ${ }^{3}$ Persistent frequent exposure to the hypopharynx by gastric contents can lead to laryngeal leukoplakia, laryngeal granulomata, and subglottic stenosis, and may serve as a co-factor in the development of laryngeal cancer. ${ }^{4}$ Additionally, LPR is reported to have a more significant impact on patients' social functioning and vitality compared to typical GERD. ${ }^{5}$

The diagnosis of LPR has traditionally been made based on the presence of laryngeal symptoms and laryngoscopic findings such as erythema, edema, ventricular obliteration, postcricoid hyperplasia, and pseudosulcus. ${ }^{6}$ However, the sensitivity and specificity of these laryngoscopic findings are poor, and they are identified in up to $86 \%$ of healthy asymptomatic subjects. ${ }^{7}$ Dual-channel $24-\mathrm{h}$ pH monitoring with esophageal and pharyngeal $\mathrm{pH}$ probes has been shown to be effective to detect LPR. ${ }^{8,9}$ However, the pharyngeal $\mathrm{pH}$ 
probe is poorly sensitive secondary to the relatively alkaline environment within the proximal aerodigestive tract; distal acid events become neutralized by saliva as they move proximally from the stomach to the hypopharynx. In addition, this testing is limited to detect acid LPR, not non-acid LPR which also has caustic properties. Based on this, the guideline of the American College of Gastroenterology stated that "available evidence does not support the routine use of proximal $\mathrm{pH}$ monitoring in clinical practice." 10 Therefore, there is a need for more accurate, objective testing of LPR.

Multichannel intraluminal impedance combined with $\mathrm{pH}$ monitoring (MII-pH) has been shown to be useful in patients with persistent symptoms despite acid suppression therapy. ${ }^{11,12} \mathrm{MII}-\mathrm{pH}$ enables the detection and measurement of intraesophageal bolus movement (regardless of $\mathrm{pH}$ ) by detecting a change in resistance to current flow between two electrodes when a liquid and/or gas bolus bridges them. When electrolyte-rich fluid is present between the two impedance electrodes, impedance decreases due to the flow of electrical current. In contrast, a gas event is poorly conductive and increases impedance. Based on these differences in impedance characteristics, liquid, gas, and mixed liquid-gas events can be differentiated. When multiple impedance electrode pairs are mounted on to the same catheter, the direction and extent of bolus movement can be measured. An antegrade (proximal to distal) progression of impedance changes represents swallowing, whereas a retrograde (distal to proximal) progression represents a reflux event. Furthermore, the catheter configuration can be tailored by changing the location of impedance electrodes and $\mathrm{pH}$ probes, and this can be exploited to test for LPR.

We developed a specialized impedance catheter configured to detect proximal reflux events such as LPR and full column reflux. The aim of this study was to establish the normative data for LPR in an asymptomatic cohort using hypopharyngeal multichannel intraluminal impedance-pH (HMII) and to determine if the normative data obtained can differentiate patients with pathological LPR.

\section{Materials and Methods}

\section{Study Design}

This prospective trial was performed under the approval of institutional review board of the University of Pittsburgh (PRO08070129). Subjects were recruited through community advertising using popular media (news paper, flyers, word of mouth). Inclusion criteria consisted of all asymptomatic subjects who were in good health and able to safely tolerate unsedated transnasal endoscopy. Prior to enrollment, subjects completed a general medical and social history questionnaire to rule out disorders of the upper gastrointestinal or respiratory tracts. Absence of symptoms was confirmed by a score of zero on both the GERD-HRQoL questionnaire ${ }^{13}$ and reflux symptom index. ${ }^{14}$ Exclusion criteria included age $<18$ and $>80$ years, any past history of GERD (symptoms, medical treatment, endoscopic findings, or antireflux surgery) and LPR symptoms such as globus sensation, chronic cough, dysphonia, and throat clearing. Factors that potentially increased the risk of transnasal endoscopy such as pregnancy, diverticulum, esophageal varices, and a history of epistaxis were also considered exclusion criteria. All subjects underwent unsedated transnasal endoscopy to exclude esophageal pathology such as esophagitis, hiatal hernia, 
Hill classification grade III or IV valve, inlet patch (ectopic gastric mucosa), and/or Barrett's esophagus. HMII-pH was then performed before and after a 2-week course of proton pump inhibitors (PPI) (Omeprazole $20 \mathrm{mg}$, BID). Participants were instructed to take the medication on an empty stomach, 30 min prior to a meal twice each day. ${ }^{15}$

\section{Unsedated Transnasal Endoscopy}

Subjects were fasted overnight prior to unsedated transnasal endoscopy. The subject was placed in the sitting position and $7 \mathrm{ml}$ of aerosolized $4 \%$ lidocaine was instilled using an atomizer (Wolf Tory Medical, Salt Lake City, UT) into bilateral nares over a 5-min period. A 4.7-mm-diameter flexible endoscope (TNE-5000, Vision-Sciences, Inc., Orangeburg, NY), $65 \mathrm{~cm}$ in length, was placed inside a sterile sheath (EndoSheath ${ }^{\circledR}$, Vision-Sciences, Inc., Orangeburg, NY), which provided a durable, protective barrier as well as a coaxial 2.1 $\mathrm{mm}$ biopsy channel, and was then inserted transnasally into the most patent naris. The mucosa of the nasopharynx, oropharynx, and hypopharynx was examined, and indirect laryngoscopy was performed. With the neck in flexion, the endoscope was passed into the esophagus in coordination with a swallow. The entire esophagus and proximal stomach were examined to rule out mucosal and anatomic abnormalities. Retroflexion was performed to evaluate the appearance of gastroesophageal valve; patients were excluded for a Hill Classification grade III or IV valve. ${ }^{16}$ A solution of water and simethicone (Gold-line Laboratories Inc., Miami, FL) was used to irrigate the field and obtain optimal exposure during the procedure. The distance of the esophagogastric junction was measured and recorded. We defined the location of anatomic esophagogastric junction as the distance in centimeters from the naris to the most proximal termination of the gastric folds.

\section{Hypopharyngeal Multichannel Intraluminal Impedance Combined with pH Monitoring (HMII-pH)}

A specialized, bifurcated impedance catheter with a $2.3 \mathrm{~mm}$ of outer diameter configured to detect both acid and non-acid LPR (CZAI-B62C47E) (Sandhill Scientific, Inc., Highlands Ranch, CO) was fabricated and employed in this study (Fig. 1). The long arm branch of the catheter had two electrode pairs positioned at 3 and $5 \mathrm{~cm}$ proximal to the esophagogastric junction with the $\mathrm{pH}$ sensor positioned $5 \mathrm{~cm}$ proximal to the junction. The short arm branch had two electrode pairs each in the proximal esophagus and the hypopharynx with the second $\mathrm{pH}$ sensor located $0.5 \mathrm{~cm}$ proximal to the upper border of the cricopharyngeus muscle.

The impedance catheter was calibrated immediately prior to placement using reference solutions (Sandhill Scientific, Inc., Highlands Ranch, CO). An external reference electrode was attached to the anterior chest wall over the mid-sternum. After the location of the esophagogastric junction was endoscopically measured, the long branch of catheter was placed transnasally such that the esophageal $\mathrm{pH}$ sensor was located $5 \mathrm{~cm}$ proximal to the esophagogastric junction. The short branch of the catheter was then placed through the same naris under endoscopic guidance, and the blue visual positioning band was placed at the upper border of the cricopharyngeus muscle. The positions (in centimeters) of both catheter branches were recorded so that the second "on PPI" HMII-pH catheter placement could be performed without endoscopic guidance. The catheter was secured on to the participant's 
face and neck with a transparent adhesive covering (3M, St. Paul, MN) in order to avoid displacement. The catheter was attached to an ambulatory recording device, and the total testing period was $24 \mathrm{~h}$ in length. Subjects were encouraged to attempt to maintain their usual activities, sleep schedule, and eating habits during the testing period. Subjects were instructed on how to record meal times and body position (supine, upright) changes.

\section{Test Interpretation and Reflux Definitions}

Data were transferred and analyzed using dedicated software (Bioview Analysis ${ }^{\mathrm{TM}}$, Sandhill Scientific Inc., Highlands Ranch, CO). A retrograde 50\% fall in impedance from the mean baseline impedance between the two electrode pairs indicated the presence of liquid-only reflux. The mean was calculated from baseline impedance values measured $5 \mathrm{~s}$ prior to the decrease. Gas reflux was defined as an abrupt increase in impedance $>3,000 \Omega$ in any two consecutive impedance sites with one site having an absolute value $>7,000 \Omega$. Mixed liquidgas reflux was defined as an abrupt increase in impedance (gas) occurring during or immediately before liquid reflux. LPR events were considered present with retrograde bolus transit across all ring sets that ultimately reached the hypopharynx (Fig. 2). In addition to this impedance finding, LPR was categorized into three groups based on $\mathrm{pH}$ in esophagus and hypopharynx: (1) acid LPR when both $\mathrm{pH}$ were <4, (2) non-acid LPR when both $\mathrm{pH}$ were $>4$, and (3) acid to nonacid LPR when esophageal $\mathrm{pH}$ was $<4$ but pharyngeal $\mathrm{pH}$ was $>4$. Full column reflux was defined as reflux that reached the impedance site $2 \mathrm{~cm}$ distal to the cricopharyngeus muscle but did not reach the hypopharyngeal ring set. Acid exposure time (percent) was defined as the total time $\mathrm{pH}<4$ divided by the time monitored. DeMeester score was calculated for the distal $\mathrm{pH}$ monitor using established criteria. ${ }^{17}$ Meal times were excluded from analysis. All tracings were individually reviewed to determine the type of reflux events and the proximal extent as measured by impedance and $\mathrm{pH}$.

\section{Comparison with "True LPR” Patients}

For comparison with the normative data, a cohort of patients was selected based on the presence of pre-treatment confirmed LPR and atypical symptoms and a subsequent complete response to medical or surgical therapy. From October 2009 to October 2010, 202 patients with GERD and/or LPR symptoms underwent HMII-pH using the same catheter configuration as in the asymptomatic cohort. Eighteen patients were excluded because of sensor noise. All tracings were analyzed in an identical manner as outlined for the asymptomatic cohort. Of 184,38 patients $(20.7 \%)$ had one or more LPR events detected during 24-h HMII-pH. Of 38, 24 patients had pre-treatment documented LPR ( $>1$ event detected by HMII-pH with the same catheter configuration) with LPR predominate symptoms (LPR symptoms alone or LPR symptoms coupled with heartburn and/or regurgitation). Of them, 10 patients had a complete response with PPI therapy and 14 patients had symptom resolution with antireflux surgery after an incomplete response to medical therapy. Post-operative symptoms were assessed based on personal interview at 6 weeks and 1 year after initiating therapy. As part of an on-going quality assurance initiative, patients are contacted at these intervals and asked symptom resolution and satisfaction to treatment. A "complete response" was considered achieved when pre-treatment symptoms were completely resolved with good patients' satisfaction to treatment. A large number of these patients had pre-treatment esophagitis or hiatal hernia (Table 1). 


\section{Data Analysis}

Values were expressed as median, interquartile range, and 95th percentile values. The 95th percentile of each type of reflux event was calculated using a Poisson distribution. The 95th percentile values represent the upper limit of normative data for 24-h HMII-pH and were used as cut-off points between normal vs. abnormal. Because experimental data were not normally distributed, statistical analysis was performed by means of the non-parametric Wilcoxon signed rank test using SPSS software (ver. 18.0) and a $p$ value $<0.05$ was considered significant.

\section{Results}

\section{Subject Population}

From a total of 75 subjects who responded to the advertisements, 40 subjects (18 male, 22 female) were enrolled in this study. Mean age and body mass index were 33 years (range, 19-59 years) and 26.1 (range, 17.5-40), respectively. All 40 subjects underwent unsedated transnasal endoscopy followed by HMII-pH off PPI. Six subjects were excluded because of a positive DeMeester score $(n=3)$ or improper recording such as sensor noise and short duration of study $(n=3)$. These three subjects with a positive DeMeester score were excluded. Following a 2-week course of PPI, 33 subjects underwent the second HMII-pH on PPI. Five subjects were excluded because of improper recording. As a result, complete data sets were available for 34 and 25 subjects off and on PPI, respectively (Fig. 3).

\section{LPR and Full Column Events in Normal Subjects}

One of the 34 subjects who completed HMII off PPI had 1 LPR event, and 2 of 25 subjects who completed HMII on PPI had 1 and 3 LPR events, respectively. Based on the 95th percentile values, the normal values of LPR off and on PPI were 0 and 1 , respectively. The normal value of full column reflux ( $2 \mathrm{~cm}$ distal to the cricopharyngeus muscle) was 4 for both off and on PPI. There was no significant difference in the total number of reflux events between off and on PPI (median, 22 and 24, respectively; $p=0.89$ ). The 95th percentile values of total reflux events (any reflux into the esophagus) off and on PPI were 48 and 40, respectively. Most hypopharyngeal acid exposure off and on PPI occurred in the upright position (median, 0.9 and 0.5 , respectively) compared to the supine position (median, both 0). Of total reflux events, $87.4 \%$ off PPI and $80 \%$ on PPI occurred in the upright position. The values in each component of acid exposure time between off and on PPI were not significantly different (Table 2).

\section{Composition and Patterns of Proximal Reflux Events}

We defined proximal exposure as LPR combined with full column reflux. Of total reflux events into the esophagus, proximal exposure was $7 \%$ in normal subjects both off and on PPI, compared to greater than $50 \%$ in LPR patients, even though there was no significant difference in the total number of reflux events between groups (Table 3). Although most of LPR events in normal subjects were acid, nearly $40 \%$ of LPR events in LPR patients were non-acid in the hypopharynx. Thirty percent of LPR events in LPR patients were acid in the distal esophagus but turned non-acid in the hypopharynx. In terms of composition, most of 
LPR events in normal subjects were liquid, whereas half of LPR events in LPR patients were mixed (liquid and gas). On the other hand, there was essentially no difference in composition of full column reflux between normal subjects and LPR patients, a half of which were mixed (Table 4).

\section{Comparison of LPR Patients with the Normative Data}

The HMII values of LPR and full column reflux events in LPR patients were significantly greater than those in normal subjects despite no significant difference in the total number of reflux events between groups (Table. 5). In particular, there was no overlap of LPR values between groups (Fig. 4). The majority of proximal events such as LPR and full column reflux occurred in the upright position in both groups. Although DeMeester score in LPR patients was significantly higher than in normal subjects, a large number of LPR patients had a negative DeMeester score, which may reflect the fact that there was no significant difference in the total number of reflux events between groups.

\section{Discussion}

LPR symptoms have been recognized as a common entity, affecting an estimated $20 \%$ of the adult population in the USA. ${ }^{18}$ However, laryngeal symptoms are non-specific and can be associated with smoking, toxic inhalants, environmental allergies, and postnasal discharge with or without any defined organic origin. ${ }^{19}$ As an initial diagnostic measure, it is currently recommended that patients be started on an empiric 3-month trial of high-dose PPI. ${ }^{19}$ However, PPI therapy is associated with a significant placebo effect and most controlled trials have failed to demonstrate any benefit in patients with suspected LPR related laryngeal symptoms. ${ }^{20,21}$ Two recent meta-analysis have demonstrated the absence of therapeutic benefit of PPIs in this setting. ${ }^{22,23}$ Similarly, the outcomes of surgical fundoplication in patients with laryngeal symptoms have been less effective than for patients with typical symptoms of GERD. ${ }^{24-28}$

Previous studies have suggested that a direct measure of LPR will be essential to guide treatment in LPR patients and that this will ultimately lead to improved outcomes. A " $\mathrm{pH}$ centric" focus and lack of symptom correlation in the setting of LPR are important factors that contribute to the low sensitivity and specificity of currently available testing modalities. It is important to consider that LPR symptoms may be caused by direct gastric fluid exposure to the hypopharynx (direct mechanism) or vagal-mediated bronchoconstriction due to gastric fluid exposure to the distal esophagus (indirect mechanism), ${ }^{2}$ and a symptom index is therefore difficult to interpret and depend upon in establishing a diagnosis.

Furthermore, LPR events appear to be rare even in patients with "true LPR" and therefore a composite scoring system for LPR (similar to the DeMeester score used for GERD) may therefore be difficult to establish. Finally, as demonstrated in the present study, a majority of LPR events are either non-acid or weakly acid and would not be detected with extraesophageal $\mathrm{pH}$ monitoring configurations.

Several studies have demonstrated the usefulness of MII-pH to evaluate patients with $\mathrm{LPR}^{24,29,30}$ and that the proximal extent of reflux, rather than non-acid reflux, may play a more important role in the development laryngeal symptoms. ${ }^{29}$ The impedance catheter used 
in previous studies had impedance electrode pairs and $\mathrm{pH}$ probes only in the esophagus (distal and proximal), not in the hypopharynx. These catheters were therefore not optimized to directly measure LPR. A limitation to the implementation of hypopharyngeal impedance testing has been related to excessive noise secondary to air exposure and swallowing over the paired electrodes. Oelschlager et al. utilized a specially designed bifurcated impedance catheter, in which one branch had four impedance electrode pairs $(3,5,7$, and $9 \mathrm{~cm}$ above the gastroesophageal junction (GEJ)) and esophageal $\mathrm{pH}$ probe $(5 \mathrm{~cm}$ above the GEJ), and the other branch had a pharyngeal $\mathrm{pH}$ sensor $(2 \mathrm{~cm})$ above the upper esophageal sphincter (UES) and a pair of impedance electrodes below $(5 \mathrm{~cm})$ and above $(2 \mathrm{~cm})$ the UES. ${ }^{31}$ The results of MII-pH with this catheter on ten healthy subjects showed that the median number of pharyngeal reflux was 5 , which is higher than the number observed in the present study. This catheter had only one pair of electrodes in the hypopharynx, and it may have been difficult to differentiate pharyngeal reflux from the initiation of a swallow. In contrast, the catheter used in the present study had two pairs of impedance electrodes each in the distal and proximal esophagus as well as the hypopharynx. Therefore, antegrade versus retrograde bolus movement could be effectively differentiated and LPR confirmed as retrograde bolus transit "tracked" along the entire esophagus and into the hypopharynx. The modifications that enabled extraesophageal impedance measurements to be obtained in this study included close spacing of electrode pairs adjacent to the $\mathrm{pH}$ probe and placement of the electrodes immediately proximal to the upper border of the cricopharyngeus muscle. This catheter configuration and placement technique was achieved by trial and error in pilot work until proximal noise was eliminated.

Although there are studies demonstrating normal values for 24-h MII-pH off PPI, ${ }^{32-35}$ this is the first report to provide the normative data of each reflux event for 24-h HMII-pH both off and on PPI in the same individual. Since empiric PPI therapy has been commonly used in patients with possible LPR, we desired to assess the effect of PPI on the patterns of reflux in the context of this novel catheter. Our results indicate that there was a trend towards more LPR events seen on PPI than off PPI (0 off PPI vs. 1 on PPI) despite no significant difference in the total number of reflux events between off and on PPI. The reason for this remains unclear. On the other hand, "full column reflux" is a different entity than "proximal reflux" reported previously. Conventional "proximal reflux" has been defined as reflux that reaches $15 \mathrm{~cm}$ above the LES, whereas "full column reflux" is define as reflux that reaches the impedance site $2 \mathrm{~cm}$ below the UES. In a previous multicenter trial to determine normative data for 24-h MII-pH, ${ }^{32}$ Shay et al. demonstrated that the normal value of conventional "proximal reflux" is 31 events. Our result indicates that "full column reflux" is a much rarer event compared to conventional "proximal reflux" (normal value, 4 vs. 31, respectively). Interestingly, approximately $45 \%$ of total reflux events were full column reflux in patients with treatment responsive LPR. The number of full column reflux events may potentially be used as a predictor of pathological LPR.

Given the fact that a large number of patients with treatment responsive LPR had a negative DeMeester score as well as an abnormal number of total reflux events implies that traditional $\mathrm{pH}$ testing would not be sensitive enough to make the diagnosis of LPR in these patients. In addition, nearly $40 \%$ of LPR events were non-acid in the hypopharynx and therefore these events would not be detected by conventional dual-channel $\mathrm{pH}$ monitoring. 
Recently, the Restech pH catheter (Respiratory Technology Corp., San Diego, CA) has been reported to be a sensitive and minimally invasive device for detection of acid reflux in the posterior orophayrnx.${ }^{36}$ However, it should be noted that a substantial number of LPR events are non-acid in the oropharynx, and this technique may therefore underestimate the disease. In contrast, the impedance catheter used in the present study successfully detected all forms of LPR. All patients with treatment responsive LPR had a pre-treatment HMII value of LPR greater than the 95th percentile value of LPR in normal subjects. This indicates that the specificity of HMII with this catheter is very high. However, the sensitivity of this catheter is unknown because there has been no way to detect "true LPR" other than our system and a false-negative rate cannot be determined.

In conclusion, HMII-pH appears to be an extremely promising test to objectively measure events of LPR. This study establishes the normative data for LPR using HMII-pH with a specialized impedance catheter. LPR events are extremely rare in patients without GERD or LPR symptoms as measured with HMII-pH. One or more LPR events should be considered abnormal in patients with LPR symptoms regardless of whether there is a positive DeMeester score.

\section{Appendix}

Discussant

Dr. John F. Sweeney (Atlanta, GA): Good morning and Happy Mother's Day. My name is John Sweeney and I am Chief of General and Gastrointestinal Surgery at Emory University in Atlanta. I would like to take the opportunity to thank the Society for the opportunity to discuss this manuscript. Before I begin, I would like to congratulate Dr. Hoppo on a fine presentation. In addition I would like to thank the authors for providing me a copy of their manuscript for review well in advance of the meeting. It is clearly and concisely written. I have three questions:

1. The manuscript states that healthy subjects were recruited through community advertising. How did you incentivize their participation? Were they paid? If so, when did this occur? After each completed test? At the end of the entire experiment? What happened if they completed the tests but the data were not felt to be usable? Were they still paid?

2. The next question is regarding the LPR treatment responsive group. The manuscript states that subjects were selected from a group of patients with atypical symptoms of LPR that had a complete response to medical or surgical therapy. Were there any differences in impedance results for each subgroup of patients?

3. As you clearly state in the discussion of your manuscript, the outcomes for either medical or surgical management of LPR can vary significantly. How will the results of this study lead to better stratification of patients with LPR to the modality that they are most likely to respond? More importantly, do you envision that this modality will help us identify patients that will not respond to a fundoplication and therefore in whom surgery should therefore be avoided? 
Again, I would like to thank the Society for the privilege of discussing this paper and congratulate the authors on a well-designed and well-executed study.

\section{Closing Discussant}

Dr. Toshitaka Hoppo: Thank you very much for your great comments and questions, Dr. Sweeney.

1. The first question was regarding incentive for participants. All participants were paid twice after each impedance testing. They were paid $\$ 125$ after the placement of the first impedance catheter and $\$ 75$ after the placement of the second impedance catheter. They were still paid if the data were not usable.

2. The second question was regarding difference in LPR events in patients who responded to medical therapy and surgical therapy. When looked at the difference in the number of LPR events on impedance testing, there was a trend towards more LPR events observed in surgical therapy responsive patients compared to medical therapy responsive patients ( 3 vs. $1.2 /$ day). This may be explained by that more LPR events cannot be controlled well by medical therapy.

3. The last question was regarding the stratification with impedance testing. This is a good question. It is important to determine who would benefit from the treatment and what treatment would be the best. The impedance testing can make a diagnosis of LPR but cannot tell us what the best treatment would be for each patient. However, making an accurate diagnosis of LPR should contribute to the better outcomes of treatments.

\section{References}

1. Koufman JA. The otolaryngologic manifestations of gastroesophageal reflux disease (GERD): a clinical investigation of 225 patients using ambulatory 24-hour $\mathrm{pH}$ monitoring and an experimental investigation of the role of acid and pepsin in the development of laryngeal injury. Laryngoscope. 1991 Apr; 101(4 Pt 2 Suppl 53):1-78. [PubMed: 1895864]

2. Lang IM, Haworth ST, Medda BK, Roerig DL, Forster HV, Shaker R. Airway responses to esophageal acidification. Am J Physiol Regul Integr Comp Physiol. 2008 Jan; 294(1):R211-R219. [PubMed: 17928508]

3. Barry DW, Vaezi MF. Laryngopharyngeal reflux: More questions than answers. Cleve Clin J Med. 2010 May; 77(5):327-334. [PubMed: 20439565]

4. Vaezi MF, Qadeer MA, Lopez R, Colabianchi N. Laryngeal cancer and gastroesophageal reflux disease: a case-control study. Am J Med. 2006 Sep; 119(9):768-776. [PubMed: 16945612]

5. Carrau RL, Khidr A, Crawley JA, Hillson EM, Davis JK, Pashos CL. The impact of laryngopharyngeal reflux on patient-reported quality of life. Laryngoscope. 2004 Apr; 114(4):670 674. [PubMed: 15064622]

6. Book DT, Rhee JS, Toohill RJ, Smith TL. Perspectives in laryngopharyngeal reflux: an international survey. Laryngoscope. 2002 Aug; 112(8 Pt 1):1399-1406. [PubMed: 12172252]

7. Hicks DM, Ours TM, Abelson TI, Vaezi MF, Richter JE. The prevalence of hypopharynx findings associated with gastroesophageal reflux in normal volunteers. J Voice. 2002 Dec; 16(4):564-579. [PubMed: 12512644]

8. Koufman JA, Aviv JE, Casiano RR, Shaw GY. Laryngopharyngeal reflux: position statement of the committee on speech, voice, and swallowing disorders of the American Academy of 
Otolaryngology-Head and Neck Surgery. Otolaryngol Head Neck Surg. 2002 Jul; 127(1):32-35. [PubMed: 12161727]

9. Lee BE, Kim GH, Ryu DY, et al. Combined Dual Channel Impedance/pH-metry in Patients With Suspected Laryngopharyngeal Reflux. J Neurogastroenterol Motil. 2010 Apr; 16(2):157-165. [PubMed: 20535346]

10. Hirano I, Richter JE. ACG practice guidelines: esophageal reflux testing. Am J Gastroenterol. 2007 Mar; 102(3):668-685. [PubMed: 17335450]

11. Vela MF. Non-acid reflux: detection by multichannel intraluminal impedance and $\mathrm{pH}$, clinical significance and management. Am J Gastroenterol. 2009 Feb; 104(2):277-280. [PubMed: 19190606]

12. Agrawal A, Castell DO. Clinical importance of impedance measurements. J Clin Gastroenterol. 2008 May-Jun;42(5):579-583. [PubMed: 18364586]

13. Velanovich V. The development of the GERD-HRQL symptom severity instrument. Dis Esophagus. 2007; 20(2):130-134. [PubMed: 17439596]

14. Belafsky PC, Postma GN, Koufman JA. Validity and reliability of the reflux symptom index (RSI). J Voice. 2002 Jun; 16(2):274-277. [PubMed: 12150380]

15. Hatlebakk JG, Katz PO, Camacho-Lobato L, Castell DO. Proton pump inhibitors: better acid suppression when taken before a meal than without a meal. Aliment Pharmacol Ther. 2000 Oct; 14(10):1267-1272. [PubMed: 11012470]

16. Hill LD, Kozarek RA, Kraemer SJ, et al. The gastroesophageal flap valve: in vitro and in vivo observations. Gastrointest Endosc. 1996 Nov; 44(5):541-547. [PubMed: 8934159]

17. Johnson LF, DeMeester TR. Development of the 24-hour intraesophageal pH monitoring composite scoring system. J Clin Gastroenterol. 1986; 8 Suppl 1:52-58. [PubMed: 3734377]

18. Koufman JA, Amin MR, Panetti M. Prevalence of reflux in 113 consecutive patients with laryngeal and voice disorders. Otolaryngol Head Neck Surg. 2000 Oct; 123(4):385-388. [PubMed: 11020172]

19. Ford CN. Evaluation and management of laryngopharyngeal reflux. Jama. 2005 Sep 28; 294(12): 1534-1540. [PubMed: 16189367]

20. Fass R, Noelck N, Willis MR, et al. The effect of esomeprazole $20 \mathrm{mg}$ twice daily on acoustic and perception parameters of the voice in laryngopharyngeal reflux. Neurogastroenterol Motil. 2010 Feb; 22(2):134-141. e144-135. [PubMed: 19740116]

21. Vaezi MF, Richter JE, Stasney CR, et al. Treatment of chronic posterior laryngitis with esomeprazole. Laryngoscope. 2006 Feb; 116(2):254-260. [PubMed: 16467715]

22. Gatta L, Vaira D, Sorrenti G, Zucchini S, Sama C, Vakil N. Meta-analysis: the efficacy of proton pump inhibitors for laryngeal symptoms attributed to gastro-oesophageal reflux disease. Aliment Pharmacol Ther. 2007 Feb 15; 25(4):385-392. [PubMed: 17269993]

23. Qadeer MA, Phillips CO, Lopez AR, et al. Proton pump inhibitor therapy for suspected GERDrelated chronic laryngitis: a metaanalysis of randomized controlled trials. Am J Gastroenterol. 2006 Nov; 101(11):2646-2654. [PubMed: 17037995]

24. Mainie I, Tutuian R, Agrawal A, Adams D, Castell DO. Combined multichannel intraluminal impedance-pH monitoring to select patients with persistent gastro-oesophageal reflux for laparoscopic Nissen fundoplication. Br J Surg. Dec; 2006 93(12):1483-1487. [PubMed: 17051602]

25. So JB, Zeitels SM, Rattner DW. Outcomes of atypical symptoms attributed to gastroesophageal reflux treated by laparoscopic fundoplication. Surgery. 1998 Jul; 124(1):28-32. [PubMed: 9663248]

26. Swoger J, Ponsky J, Hicks DM, et al. Surgical fundoplication in laryngopharyngeal reflux unresponsive to aggressive acid suppression: a controlled study. Clin Gastroenterol Hepatol. 2006 Apr; 4(4):433-441. [PubMed: 16616347]

27. Westcott CJ, Hopkins MB, Bach K, Postma GN, Belafsky PC, Koufman JA. Fundoplication for laryngopharyngeal reflux disease. J Am Coll Surg. 2004 Jul; 199(1):23-30. [PubMed: 15217625]

28. Lindstrom DR, Wallace J, Loehrl TA, Merati AL, Toohill RJ. Nissen fundoplication surgery for extraesophageal manifestations of gastroesophageal reflux (EER). Laryngoscope. 2002 Oct; 112(10):1762-1765. [PubMed: 12368611] 
29. Anandasabapathy S, Jaffin BW. Multichannel intraluminal impedance in the evaluation of patients with persistent globus on proton pump inhibitor therapy. Ann Otol Rhinol Laryngol. 2006 Aug; 115(8):563-570. [PubMed: 16944654]

30. Wu JC. Combined Multichannel Intraluminal Impedance and $\mathrm{pH}$ Monitoring for Patients With Suspected Laryngopharyngeal Reflux: Is It Ready to Use? J Neurogastroenterol Motil. 2010 Apr; 16(2):108-109. [PubMed: 20535339]

31. Oelschlager BK, Quiroga E, Isch JA, Cuenca-Abente F. Gastroesophageal and pharyngeal reflux detection using impedance and 24-hour $\mathrm{pH}$ monitoring in asymptomatic subjects: defining the normal environment. J Gastrointest Surg. 2006 Jan; 10(1):54-62. [PubMed: 16368491]

32. Shay S, Tutuian R, Sifrim D, et al. Twenty-four hour ambulatory simultaneous impedance and $\mathrm{pH}$ monitoring: a multicenter report of normal values from 60 healthy volunteers. Am J Gastroenterol. 2004 Jun; 99(6):1037-1043. [PubMed: 15180722]

33. Xiao YL, Lin JK, Cheung TK, et al. Normal values of 24-hour combined esophageal multichannel intraluminal impedance and $\mathrm{pH}$ monitoring in the Chinese population. Digestion. 2009; 79(2): 109-114. [PubMed: 19295211]

34. Zentilin P, Iiritano E, Dulbecco P, et al. Normal values of 24-h ambulatory intraluminal impedance combined with pHmetry in subjects eating a Mediterranean diet. Dig Liver Dis. 2006 Apr; 38(4): 226-232. [PubMed: 16480938]

35. Zerbib F, des Varannes SB, Roman S, et al. Normal values and day-to-day variability of 24-h ambulatory oesophageal impedance-pH monitoring in a Belgian-French cohort of healthy subjects. Aliment Pharmacol Ther. 2005 Nov 15; 22(10):1011-1021. [PubMed: 16268977]

36. Sun G, Muddana S, Slaughter JC, et al. A new pH catheter for laryngopharyngeal reflux: Normal values. Laryngoscope. 2009 Aug; 119(8):1639-1643. [PubMed: 19504553] 


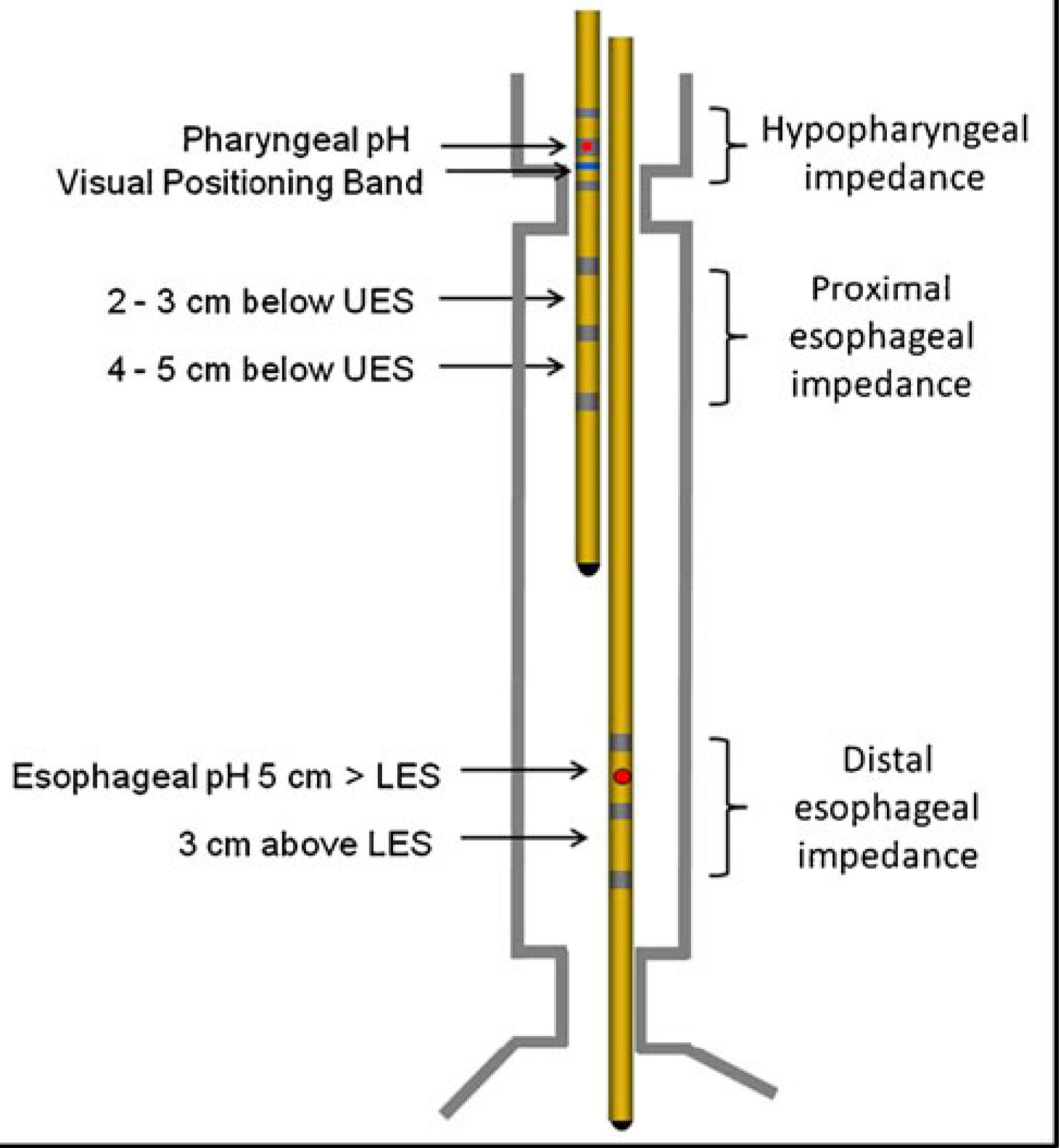

Fig. 1.

A specialized, bifurcated impedance catheter configured to detect LPR. The long arm branch of the catheter had two electrode pairs positioned at 3 and $5 \mathrm{~cm}$ proximal to the esophagogastric junction with the $\mathrm{pH}$ sensor positioned $5 \mathrm{~cm}$ proximal to the junction. The short arm branch had two electrode pairs each in the proximal esophagus and the hypopharynx with the second $\mathrm{pH}$ sensor located $0.5 \mathrm{~cm}$ proximal to the cricopharyngeus muscle 


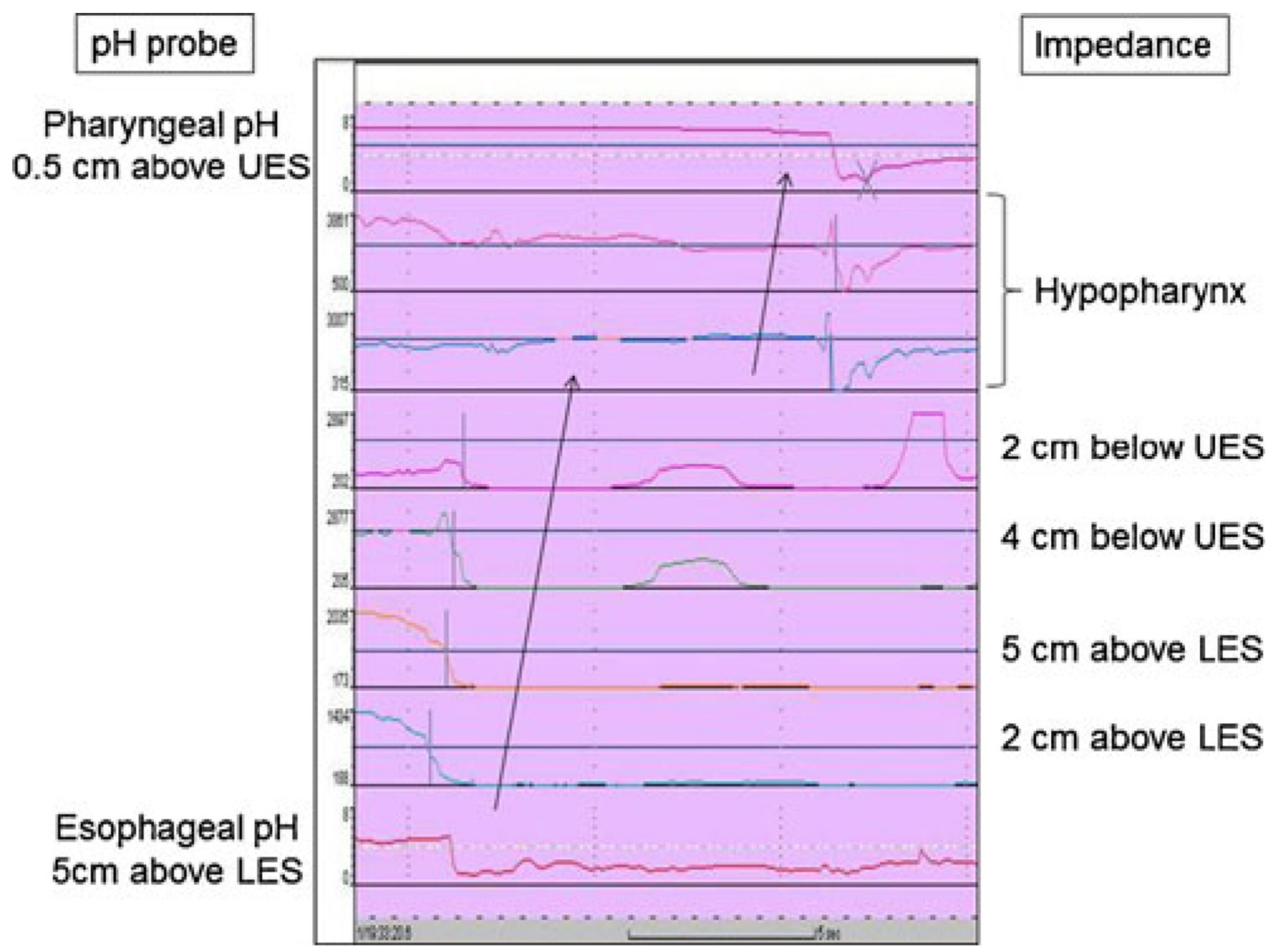

Fig. 2.

Impedance tracing of acid LPR. Acid LPR is defined when retrograde bolus transit occurs across all ring sets and ultimately reaches the hypopharynx in addition to both esophageal and pharyngeal $\mathrm{pH}$ sensors dropping $<4$ 


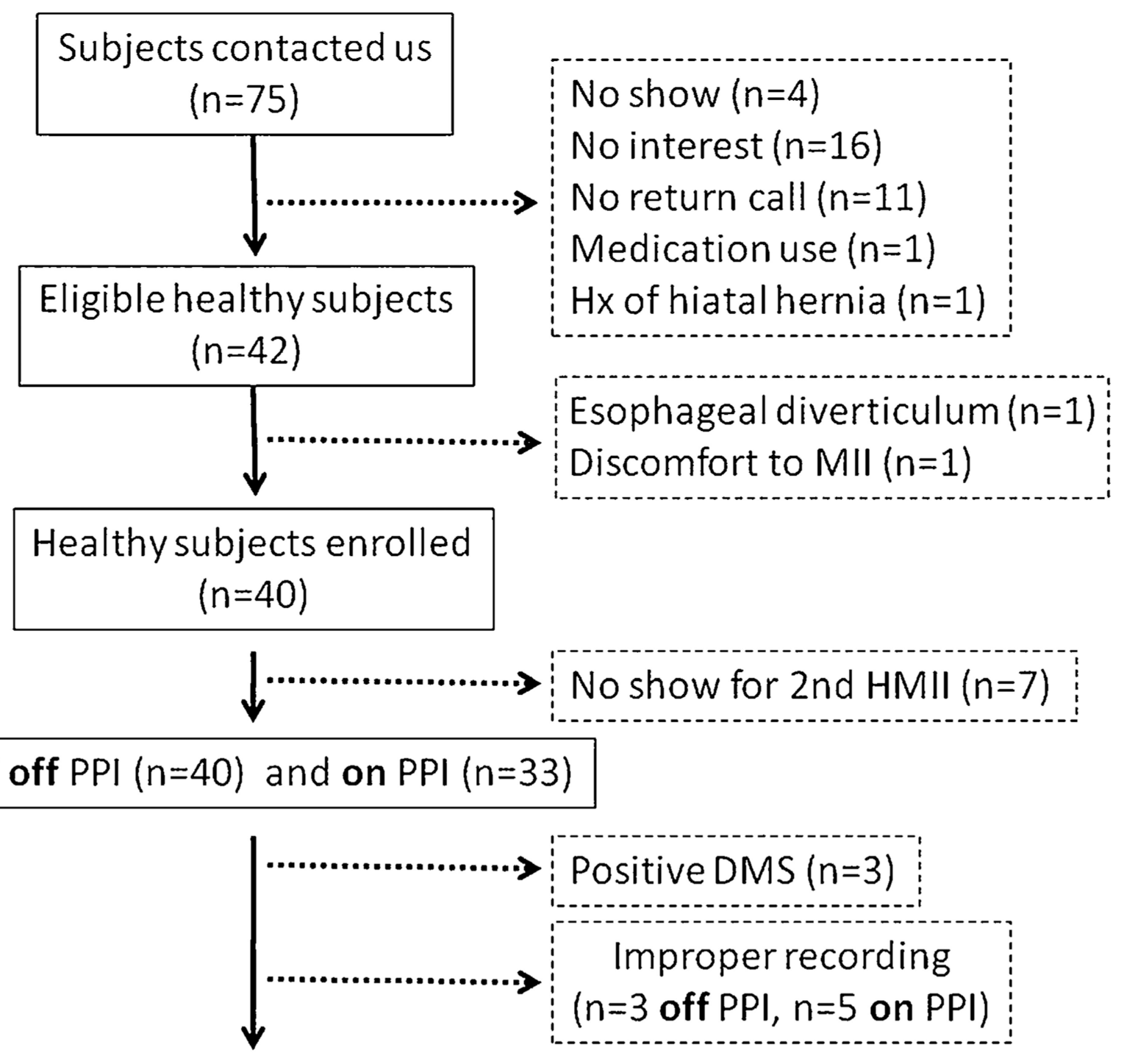

Available data off PPI $(n=34)$ and on PPI $(n=25)$

Fig. 3.

Flow chart of study subjects. From a total of 75 subjects who responded to the advertisements, 40 subjects were enrolled. Forty subjects underwent HMII off PPI and 33 on PPI. Complete data sets were available for final analysis in 34 subjects off PPI and 25 subjects on PPI 

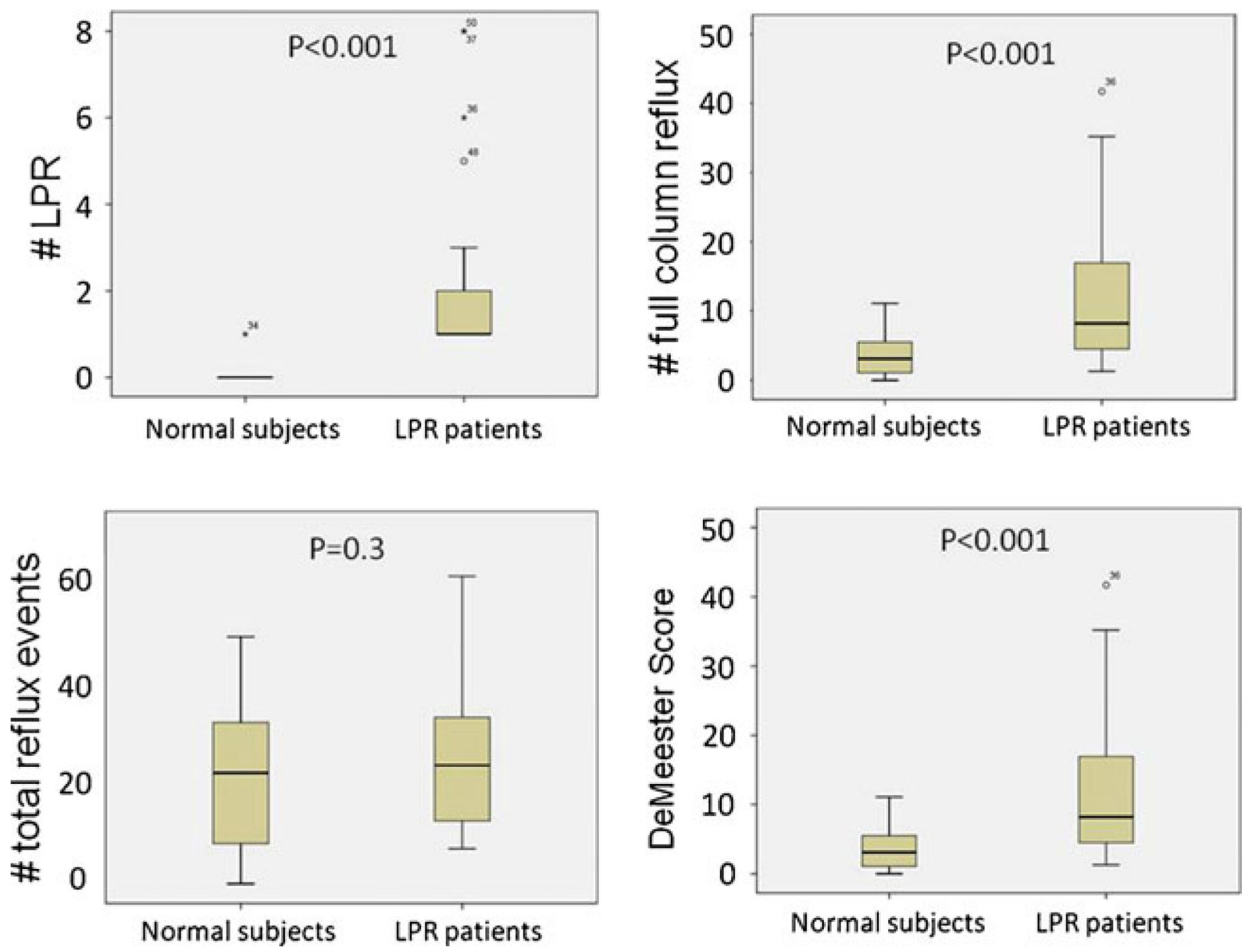

Fig. 4.

Normal subjects (off PPI) vs. treatment responsive LPR patients (off PPI). All patients with treatment responsive LPR had pre-treatment HMII values greater than the 95th percentile values of normal subjects in all criteria except total number of reflux events 


\section{Table 1}

Demographics of healthy volunteer $(n=40)$ and LPR patients $(n=24)$

\begin{tabular}{lll}
\hline & Healthy volunteer $(\boldsymbol{n = 4 0 )}$ & Treatment responsive LPR patients $(\boldsymbol{n = 2 4 )}$ \\
\hline Sex & $M=18, F=22$ & $M=6, F=18$ \\
Age (years) & 33 (range, 19-59) & $55($ range, 29-78) \\
BMI $\left(\mathrm{kg} \mathrm{m}^{-2}\right)$ & $26.1($ range, 17.5-40) & $28.4($ range, 19.1-43.8) \\
Race & Caucasian $(28)$, African-American (7), Asian (2), Hispanic (3) & Caucasian (23), African-American (1) \\
Esophagitis & 0 & $75 \%(10 / 15)$ \\
Hiatal hernia & 0 & $81.3 \%(13 / 16)$ \\
Complete response to therapy & $\mathrm{n} / \mathrm{a}$ & PPI (10), ARS (14) \\
\hline
\end{tabular}

$P P I$ proton pump inhibitor; $A R S$ antireflux surgery 
Table 3

The proportion of proximal reflux events such as LPR and full column reflux

\begin{tabular}{llll}
\hline & Off PPI $(\boldsymbol{n = 3 4})$ & On PPI $(\boldsymbol{n = 2 5})$ & Treatment responsive LPR patients $(\boldsymbol{n}=\mathbf{2 4})$ \\
\hline LPR & $0.14 \%(1 / 705)$ & $0.74 \%(4 / 542)$ & $9.3 \%(55 / 590)$ \\
Full column reflux & $6.8 \%(48 / 705)$ & $6.5 \%(35 / 542)$ & $43.4 \%(256 / 590)$ \\
Total reflux events $($ mean \pm SD $)$ & $20.7 \pm 14.5$ & $21.7 \pm 14.3$ & $24.5 \pm 14.5$ \\
\hline
\end{tabular}


Table 5

Normal subjects (off PPI) vs. treatment responsive LPR patients (off PPI)

\begin{tabular}{lccr}
\hline HMII measurements & $\begin{array}{c}\text { Normal subjects } \\
\text { (off PPI): } \boldsymbol{N = 3 4}\end{array}$ & $\begin{array}{c}\text { Treatment responsive LPR patients } \\
\text { (off PPI): } \boldsymbol{N = 2 4}\end{array}$ & $\boldsymbol{p}$ value \\
\hline Number of LPR events & $0(0-0)$ & $1(1-2)$ & $<0.001$ \\
Number of full column reflux events (2 cm distal to UES) & $1(0-2.75)$ & $9.5(5.8-17)$ & $<0.001$ \\
Number of total reflux events & $22(8.3-32)$ & $23.5(12.8-32.5)$ & 0.301 \\
DMS & $3.1(1.2-5.4)$ & $8.2(5.0-16.8)$ & $<0.001$ \\
Predominate position of events & Upright & Upright & \\
\hline
\end{tabular}

Values are expressed as a median (interquartile range). Variables were compared using the non-parametric Wilcoxon signed rank test and a $p$ value $<0.05$ was considered significant 